\title{
Isobavachalcone induces the apoptosis of gastric cancer cells via inhibition of the Akt and Erk pathways
}

\author{
$\mathrm{XIAOHONG} \mathrm{JIN}^{1}$ and $\mathrm{YI} \mathrm{SHI}^{2}$ \\ ${ }^{1}$ Department of Oncology, Yunyang People's Hospital of Danyang; ${ }^{2}$ Department of Stomatology, \\ Danyang People's Hospital of Jiangsu, Danyang, Jiangsu 212300, P.R. China
}

Received October 29, 2014; Accepted October 22, 2015

DOI: $10.3892 /$ etm.2015.2904

\begin{abstract}
In the present study, the MGC803 gastric cancer cell line was used as an experimental model to evaluate the potential role of isobavachalcone (IBC) in cell apoptosis, migration and invasion. The inhibitory effects of IBC on cell proliferation were determined using a methylthiazolyltetrazolium assay. Cellular morphological changes were assessed using Wright-Giemsa staining, and cell apoptosis was evaluated by flow cytometric analysis. The results of the present study demonstrated that IBC inhibited the proliferation of MGC803 cells in a concentration- and time-dependent manner. Furthermore, the wound healing and Matrigel ${ }^{\mathrm{TM}}$ Transwell ${ }^{\circledR}$ invasion assays demonstrated that IBC decreased cell migration and invasion in a concentration-dependent manner. Western blotting was used to determine the protein expression levels of caspase-3, B-cell lymphoma-2 (Bcl-2) and $\mathrm{Bcl}-2$-associated $\mathrm{X}$ protein (Bax), as well as the key protein kinases in the Akt and extracellular signal-regulated kinase (Erk) signaling pathways. During the IBC-induced apoptosis of MGC803 cells, transient activation of phosphorylated (p)-Akt and p-Erk inhibited the activation of Akt and Erk, upregulated Bax expression, downregulated Bcl-2 expression and activated caspase- 3 . These results suggest that IBC inhibited the growth of MGC803 gastric cancer cells by regulating the protein expression of caspase-3, Bcl-2 and Bax. In addition, inhibition of the Akt and Erk signaling pathways may be important mechanisms underlying the IBC-induced apoptosis of gastric cancer cells.
\end{abstract}

\section{Introduction}

In terms of incidence, gastric cancer is the fourth most common type of malignant tumor, with the second highest

Correspondence to: Mr. Yi Shi, Department of Stomatology, Danyang People's Hospital of Jiangsu, 2 Xin Min Road, Danyang, Jiangsu 212300, P.R. China

E-mail: shiyi6531110@163.com

Key words: isobavachalcone, gastric cancer, apoptosis, migration, invasion mortality rate $(1,2)$, as $\sim 10 \%$ of patients with cancer succumb to gastric cancer each year worldwide. Although novel chemotherapeutic drugs have emerged to improve the treatment of gastric cancer, the 5-year survival rate remains low (3). Isobavachalcone (IBC; Fig. 1) is an active ingredient isolated from Psoralea corylifolia. This Chinese herbal medicine belongs to the natural chalcones and as such has anti-inflammatory and anti-fungal effects. Previous studies have demonstrated that IBC is capable of inducing apoptosis in cancerous ovarian, breast, lung, and other tumor cells, whereas it is non-toxic to normal cells, including L-02 and human umbilical vascular endothelial cells (HUVECs) $(4,5)$. It has been suggested that IBC may be used clinically as an efficient anti-tumor drug with low toxicity (4); however, the exact molecular mechanism has yet to be elucidated.

The main characteristic of malignant tumors is that tumor cells can undergo unrestricted proliferation and apoptosis. The B-cell lymphoma (Bcl)-2 gene family is an important group of apoptosis-associated genes, which can encode anti-apoptotic proteins (Bcl-2) and pro-apoptotic proteins [Bcl-2-associated $\mathrm{X}$ protein $(\mathrm{Bax})]$. The expression of $\mathrm{Bcl}-2$ protein is generally low in normal cells, but abnormally high in tumor cells.

In order to expound the molecular mechanism of IBC-induced apoptosis in gastric cancer cells and to explore potential biological targets, various concentrations of IBC were used to treat MGC803 cells in the present study. The effects on apoptosis, migration and invasion, and the alterations in the expression levels of apoptosis-related proteins in the Akt and extracellular signal-regulated kinase (Erk) pathways were investigated.

\section{Materials and methods}

Cell culture and treatment. MGC803 human gastric cancer cells were purchased from American Type Culture Collection (Manassas, VA, USA) and cultured in RPMI 1640 (Gibco; Thermo Fisher Scientific Inc., Waltham, MA, USA) supplemented with $10 \%$ fetal bovine serum (FBS; Gibco; Thermo Fisher Scientific Inc.) and $100 \mathrm{U} / \mathrm{ml}$ penicillin/streptomycin (Nanjing KeyGen Biotech Co. Ltd., Nanjing, China). Cells were maintained in the exponential phase of growth at $37^{\circ} \mathrm{C}$ in a humidified atmosphere containing $5 \% \mathrm{CO}_{2}$. All experiments were performed using cells in the log phase. IBC (2',4',4-trihydroxy-3'-[3'-methylbut-3'-ethyl]chalcone) was a 
generous gift from the Dalian Institute Of Chemical Physics, also known as the Chinese Academy Of Sciences (Dalian, China). IBC was dissolved in dimethyl sulfoxide (DMSO) to generate a $100 \mathrm{mM}$ stock solution, and was diluted to a final concentration of $0.1 \%$ in culture media.

Cell proliferation analysis. Cell viability was determined using a methylthiazolyltetrazolium (MTT) assay (Sigma-Aldrich, St. Louis, MI, USA). A total of $6 \times 10^{3}$ MGC803 cells/well were seeded into 96 -well cell culture plates with complete growth medium and maintained for $24 \mathrm{~h}$. The treatment groups were treated with 10-60 $\mu \mathrm{M}$ IBC, and the control groups were incubated with RPMI 1640 culture media, and were cultured for 24 or $48 \mathrm{~h}$ at $37^{\circ} \mathrm{C}$. The control groups included a blank control, treated with corresponding cell culture medium, and a negative control, treated with DMSO. Cells were incubated with $20 \mu \mathrm{l} \mathrm{MTT} \mathrm{solution}(5 \mathrm{mg} / \mathrm{ml})$ for $4 \mathrm{~h}$ at $37^{\circ} \mathrm{C}$ in an atmosphere containing $5 \% \mathrm{CO}_{2}$. The formazan crystals were subsequently dissolved in $200 \mu \mathrm{l}$ DMSO. The optical density (OD) was detected by measuring absorbance at $490 \mathrm{~nm}$ using a microplate reader (xMark; Bio-Rad Laboratories Inc., Hercules, CA, USA). Survival rate was determined using the following calculation: Survival rate $=($ experimental group OD value - negative control group OD value)/(blank control group OD value - negative control group OD value) $x 100 \%$. The half-maximal inhibitory concentration $\left(\mathrm{IC}_{50}\right)$ values of IBC were calculated using SPSS version 16.0 for Windows (SPSS, Inc., Chicago, IL, USA). All experiments were repeated in triplicate, the mean values were calculated and the cell proliferation curves were generated.

Cell morphological analysis. A total of 5x10 ${ }^{5}$ MGC803 cells/well were seeded in 6-well plates and incubated overnight at $37^{\circ} \mathrm{C}$. Following a $48 \mathrm{~h}$ reaction with $40 \mu \mathrm{M}$ IBC, cells from the negative control and treatment groups were collected and centrifuged at $300 \mathrm{x}$ g for $5 \mathrm{~min}$. Cell smears were subsequently prepared and stained with Wright-Giemsa solution (Sigma-Aldrich) for $10 \mathrm{~min}$, washed with running water and dried. Cell morphological changes were observed and images were captured using a CKX31 light microscope (Olympus Corp., Tokyo, Japan).

Cell apoptosis analysis. A total of $5 \times 10^{5}$ MGC803 cells/well were cultured in 6-well plates overnight and treated with various concentrations $(0,20$ and $40 \mu \mathrm{M})$ of IBC for $48 \mathrm{~h}$. Following treatment, the cells were washed twice with phosphate-buffered saline (PBS) and resuspended in $200 \mu \mathrm{l}$ binding buffer. Subsequently, the cell suspension was stained with Annexin V-fluorescein isothiocyanate (FITC) and propidium iodide (Nanjing KeyGen Biotech Co., Ltd.) according to the manufacturer's protocol, prior to incubation for $10 \mathrm{~min}$ at $37^{\circ} \mathrm{C}$ in the dark. A FACSVerse flow cytometer (BD Biosciences, San Jose, CA, USA) was used to analyze the population of Annexin V-FITC positive cells.

Wound healing analysis. A total of $8 \times 10^{5} \mathrm{MGC} 803$ cells/well were seeded in 6-well plates and cultured in complete medium at $37^{\circ} \mathrm{C}$. Upon confluent monolayers, the cells were scratched with a sterile $20 \mu \mathrm{l}$ pipette tip to create a denuded zone through the central axis of the plate. Subsequently, the cells

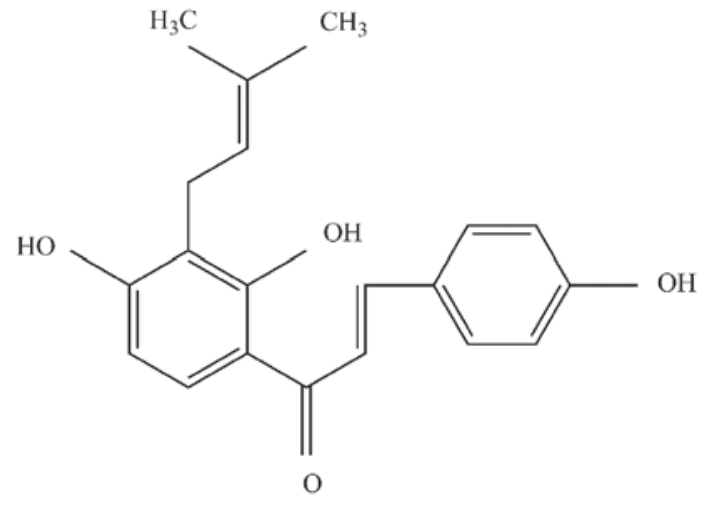

Figure 1. Isobavachalcone.

were incubated with serum-free medium supplemented with various concentrations $(0,20$ and $40 \mu \mathrm{M})$ of IBC at $37^{\circ} \mathrm{C}$. The distances of wound healing were observed and images were captured (CKX31 microscope) at 0 and $48 \mathrm{~h}$ following treatment. Cell relative motility was calculated using the following formula: Cell relative motility $=$ (average area of original wound - average area of $48 \mathrm{~h}$ wound)/average area of original wound $\mathrm{x} 100 \%$.

Cell invasion analysis. Cell invasion analysis was conducted using 24-well Transwell ${ }^{\circledR}$ chambers [unit pore size, $8 \mu \mathrm{m}$ with polyvinylidene fluoride (PVDF)] and Matrigel $^{\mathrm{TM}}$ (BD Biosciences). A total of $60 \mu$ M Matrigel $^{\mathrm{TM}}$ diluted 1:5 in serum-free medium was added to each well $4 \mathrm{~h}$ prior to cell seeding onto the upper chamber. MGC803 cells were cultured in serum-free medium with various concentrations $(0,20$ and $40 \mu \mathrm{M})$ of IBC in the upper chamber; whereas the lower chamber was filled with medium containing 10\% FBS. Following $48 \mathrm{~h}$, the cells that had migrated through the PVDF membrane and Matrigel ${ }^{\mathrm{TM}}$ to the lower surface were fixed with $4 \%$ formaldehyde and stained with $0.5 \%$ crystal violet. Cells were visually counted in five random fields using an IX51 inverted microscope (Olympus Corp.).

Western blot analysis. A total of $1 \times 10^{6} \mathrm{MGC} 803$ cells/well were cultured in 6-well plates overnight and treated with $0-40 \mu \mathrm{M}$ IBC for $48 \mathrm{~h}$. Following this, the cells were lysed using lysis buffer [50 mM Tris; $150 \mathrm{mM} \mathrm{NaCl} ; 1 \%$ Triton X-100; $1 \%$ deoxycholate; $0.1 \%$ sodium dodecyl sulfate (SDS); and 2 mM PMSF; pH 7.4] and total cellular proteins were prepared. Protein concentrations were determined using a bicinchoninic acid protein assay (Nanjing KeyGen Biotech Co., Ltd.), using bovine serum albumin as a standard. Equal amounts of protein $(20 \mu \mathrm{g})$ were separated by $12 \%$ SDS-polyacrylamide gel electrophoresis and transferred to PVDF membranes (GE Healthcare, Amersham, UK). Following 1-h incubation at $37^{\circ} \mathrm{C}$ in a blocking buffer of PBS with Tween-20 (10 mM Tris- $\mathrm{HCl}$, $150 \mathrm{mM} \mathrm{NaCl}$ and $0.1 \%$ Tween-20). and 5\% nonfat dry milk, the membranes were incubated with the following primary antibodies: Akt (1:200; cat. no. sc-8312); phosphorylated (p)-Akt (1:200; cat. no. sc-135650); Erk (1:200; cat. no. sc-94); p-Erk (1:200; cat. no. sc-16982); Bcl-2 (1:300; cat. no. sc-492); Bax (1:300; cat. no. sc-493); caspase-3 (1:200; cat. no. sc-7184; used for active caspase-3 and pro-caspase-3); and $\beta$-actin (1:1,000; 


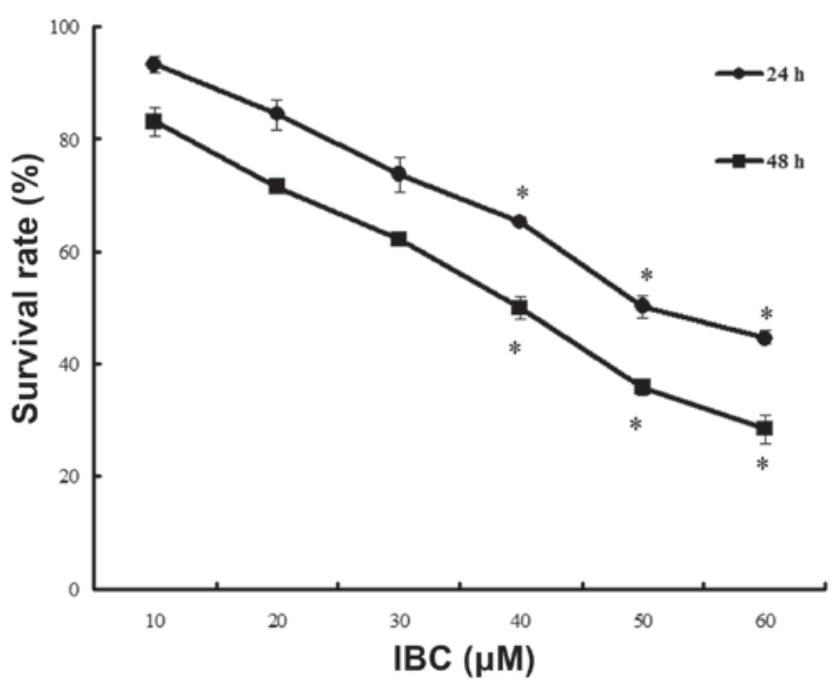

Figure 2. Isobavachalcone (IBC) inhibited the proliferation of MGC803 gastric cancer cells. Cells were treated with $10,20,30,40,50$ or $60 \mu \mathrm{M}$ IBC for 24 and $48 \mathrm{~h}$. MGC803 cell growth was measured using a methylthiazolyltetrazolium assay. Quantitative variables are expressed as the mean \pm standard deviation of three independent experiments. ${ }^{*} \mathrm{P}<0.05$ vs. control

cat. no. sc-1616; all from Santa Cruz Biotechnology, Inc., Dallas, TX, USA), overnight at $4^{\circ} \mathrm{C}$. The membranes were then treated with horseradish peroxidase-conjugated secondary antibody (1:800; cat. nos. sc-2954 and sc-2955; Santa Cruz Biotechnology, Inc.) for $2 \mathrm{~h}$. The blots were incubated with a chemiluminescence substrate (Santa Cruz Biotechnology, Inc.) and the data were corrected for loading using the values for $\beta$-actin. Immunoreactive bands were quantified using ImageJ2X software (National Institutes of Health, Bethesda, MD, USA).

Statistical analysis. Three independent experiments were performed, and statistical analyses were performed using SPSS version 16.0 software. Quantitative variables were analyzed by one-way analysis of variance and expressed as the mean \pm standard deviation. $\mathrm{P}<0.05$ was considered to indicate a statistically significant difference.

\section{Results}

IBC inhibits the proliferation of MGC803 cells. MGC803 cells were cultured in 0-60 $\mu \mathrm{M}$ IBC for 24 and $48 \mathrm{~h}$. The results of the MTT assay demonstrated that IBC inhibited the proliferation of MGC803 cells in a concentration- and time-dependent manner (Fig. 2). The $\mathrm{IC}_{50}$ values at 24 and $48 \mathrm{~h}$ were $49.68 \pm 4.26$ and $39.96 \pm 3.78 \mu \mathrm{M}$, respectively.

IBC induces apoptosis in MGC803 cells. MGC803 cells were cultured in $40 \mu \mathrm{M} \mathrm{IBC}$ for $48 \mathrm{~h}$ and the typical morphological features of apoptosis were detected using light microscopy, including apoptotic bodies (Fig. 3). Flow cytometric analysis was undertaken to verify the effect of IBC on the apoptosis of MGC803 cells. Intact cells were used as a control group. Following $48 \mathrm{~h}, 2.08 \pm 0.46 \%$ of the counted cells in the control group had become pro-apoptotic (Fig. 4). Following $48 \mathrm{~h}$ of treatment with 20 and $40 \mu \mathrm{M} \mathrm{IBC}$, the percentage of pro-apoptotic cells was $17.9 \pm 2.65$ and $34.1 \pm 3.40 \%$, respectively,
A

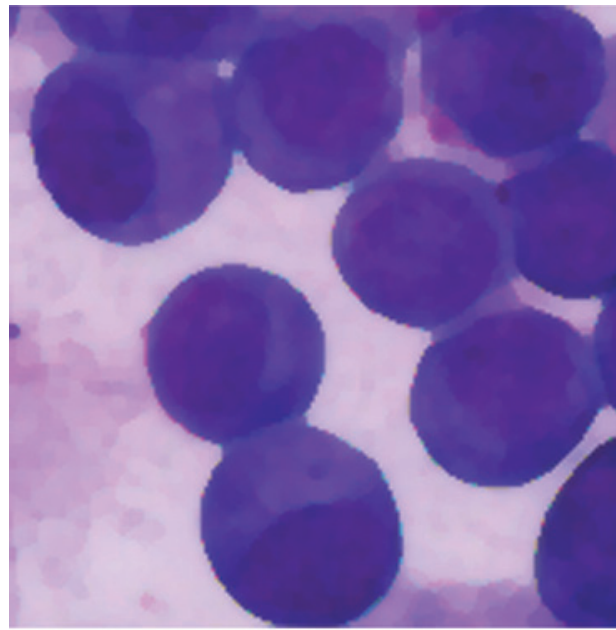

B

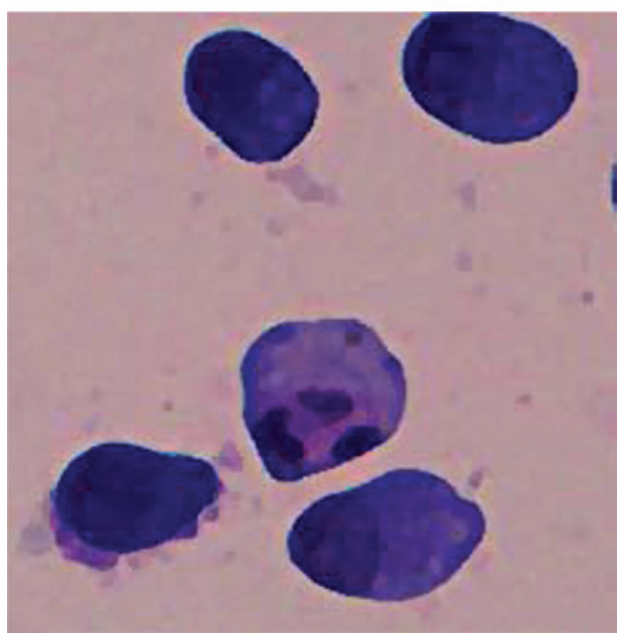

Figure 3. Isobavachalcone-induced cell apoptosis in MGC803 gastric cancer cells, as detected by light microscopy (magnification, x400). MGC803 cells were treated with (A) vehicle or (B) $20 \mu \mathrm{M}$ IBC for $48 \mathrm{~h}$.

significantly greater than that of the control groups $(n=3$, $\mathrm{P}<0.05$ ). These results indicate that IBC treatment may induce apoptosis in MGC803 cells in a concentration-dependent manner.

$I B C$ decreases migration and invasion of MGC803 cells. In order to clarify the important role of IBC in the migration and invasion of MGC803 cells, wound healing and Matrigel $^{\mathrm{TM}}$ Transwell $^{\circledR}$ invasion assays were performed. IBC administration decreased cell migration and invasion in a concentration-dependent manner (Fig. 5).

$I B C$ regulates the expression levels of proteins in MGC 803 cells. MGC803 cells were treated with 0,20 or $40 \mu \mathrm{M}$ IBC for $48 \mathrm{~h}$ and subjected to western blot analysis. IBC decreased $\mathrm{Bcl}-2$, p-Akt and p-Erk expression levels, whereas Bax and active caspase-3 protein expression levels were increased in a concentration-dependent manner (Figs. 6 and 7). As compared with the control, the $\mathrm{Bax} / \mathrm{Bcl}-2$ ratio was 2.17 and 3.96 , respectively $(\mathrm{P}<0.05)$. This result was to be expected as Bcl-2 is an anti-apoptotic protein, whereas Bax is an apoptosis-promoting protein. Furthermore, following prolonged treatment with IBC, the expression levels of active caspase-3 increased (Fig. 7). 

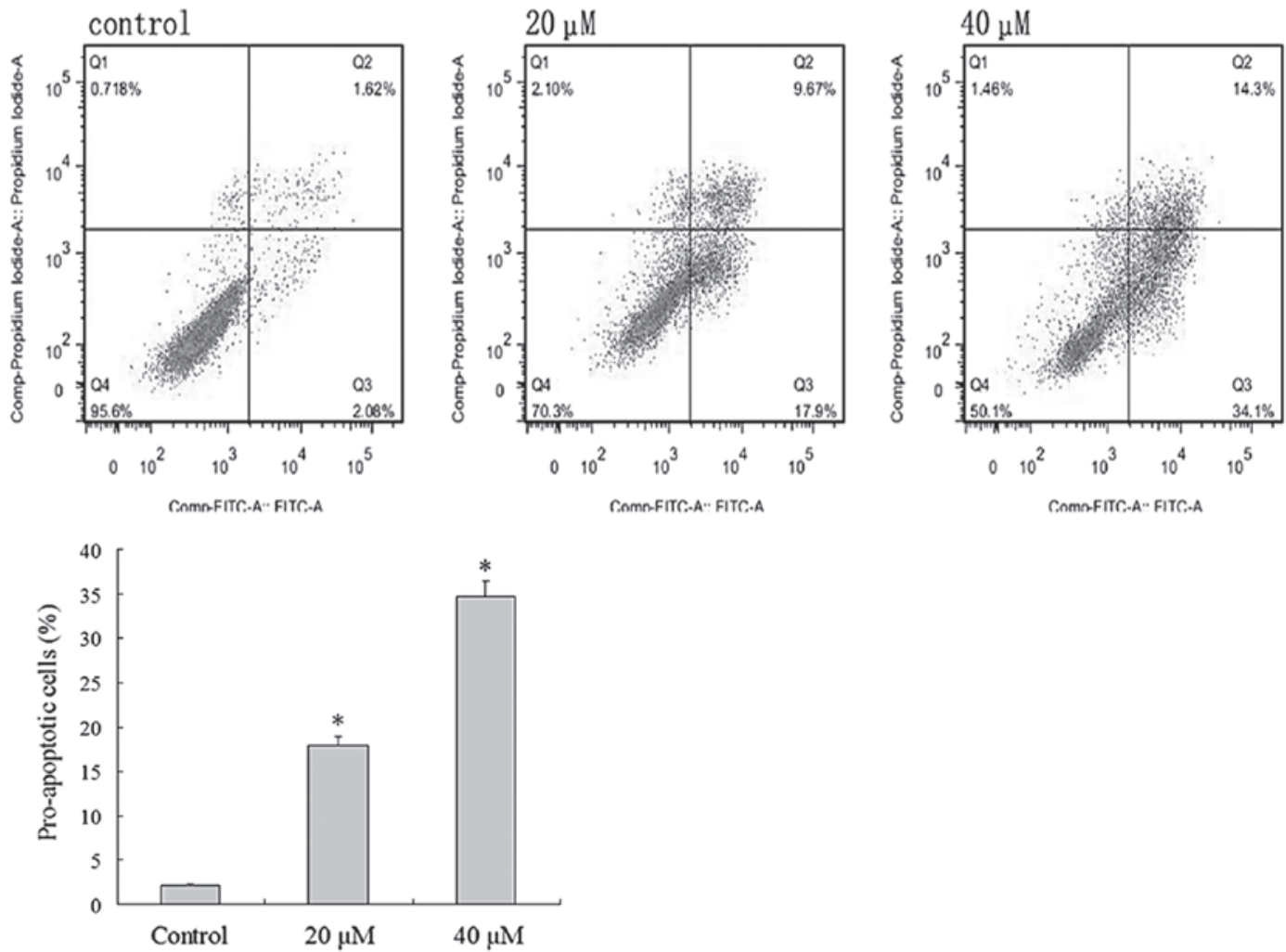

Figure 4. Flow cytometric analysis demonstrated the pro-apoptotic effects of isobavachalcone (IBC) on MGC803 gastric cancer cells. Cells were treated with 0 , 20 or $40 \mu \mathrm{M} \mathrm{IBC}$ for $48 \mathrm{~h}$. Data were derived from three independent experiments and are expressed as the mean \pm standard deviation. " $\mathrm{P}<0.05$ vs. the control. FITC, fluorescein isothiocyanate.

A
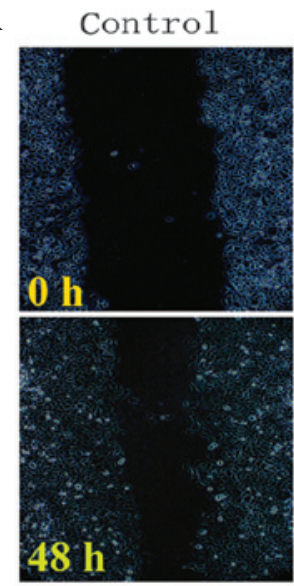

B

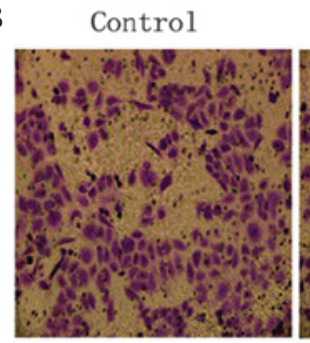

$10 \mu \mathrm{M}$
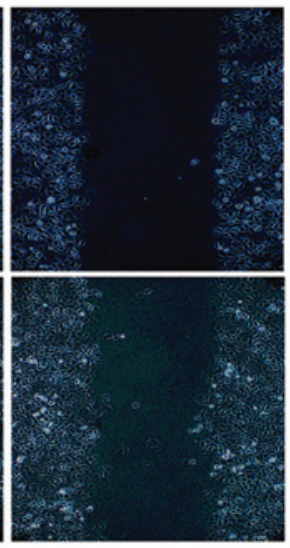

$20 \mu \mathrm{M}$

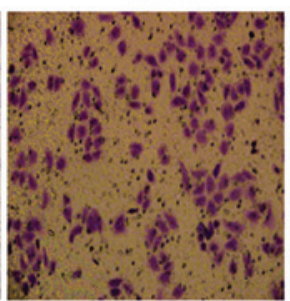

$20 \mu \mathrm{M}$
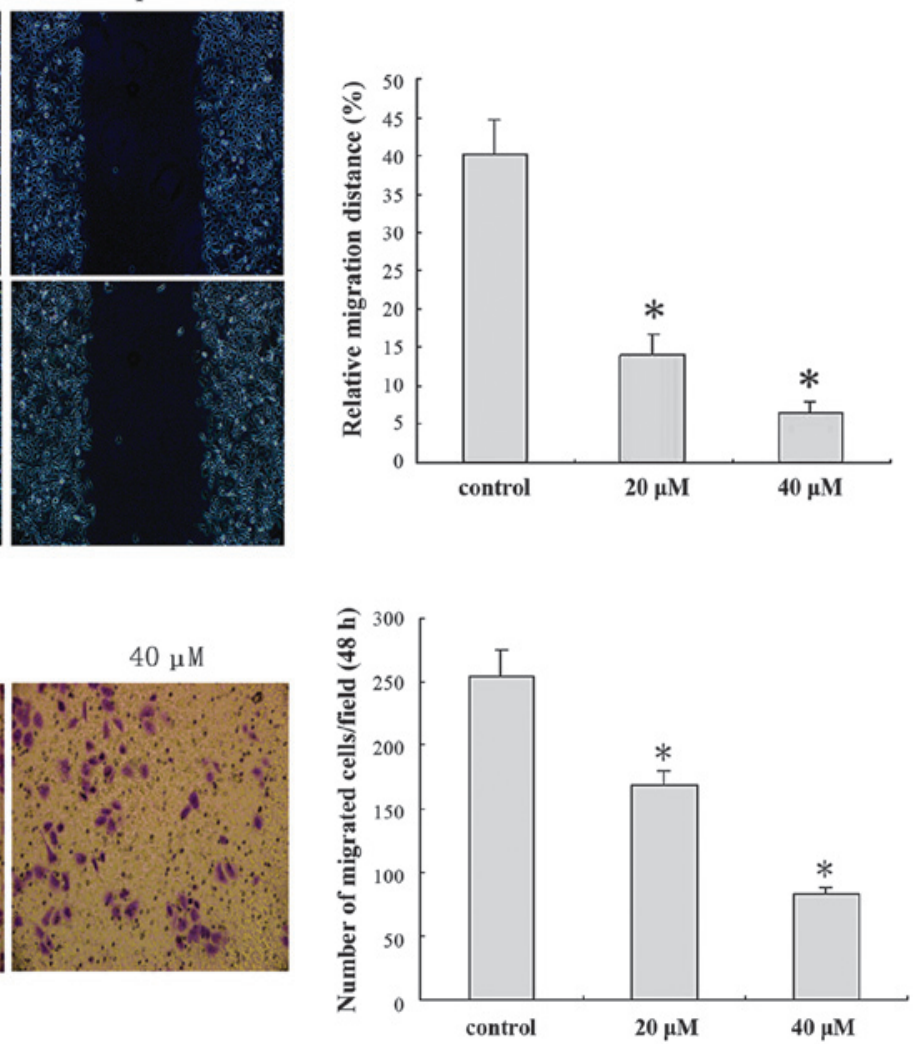

Figure 5. Isobavachalcone (IBC) decreased the migration and invasion of MGC803 gastric cancer cells. (A) Wound healing analysis demonstrated that IBC decreased migration, as detected under an optical microscope at $48 \mathrm{~h}$ (magnification, x200). (B) Transwell ${ }^{\circledast}$ assay demonstrated that IBC decreased invasion, as detected under an optical microscope at $48 \mathrm{~h}$ (magnification, x200). Data were derived from three independent experiments and expressed as the mean \pm standard deviation. ${ }^{*} \mathrm{P}<0.05$ vs. the control. 

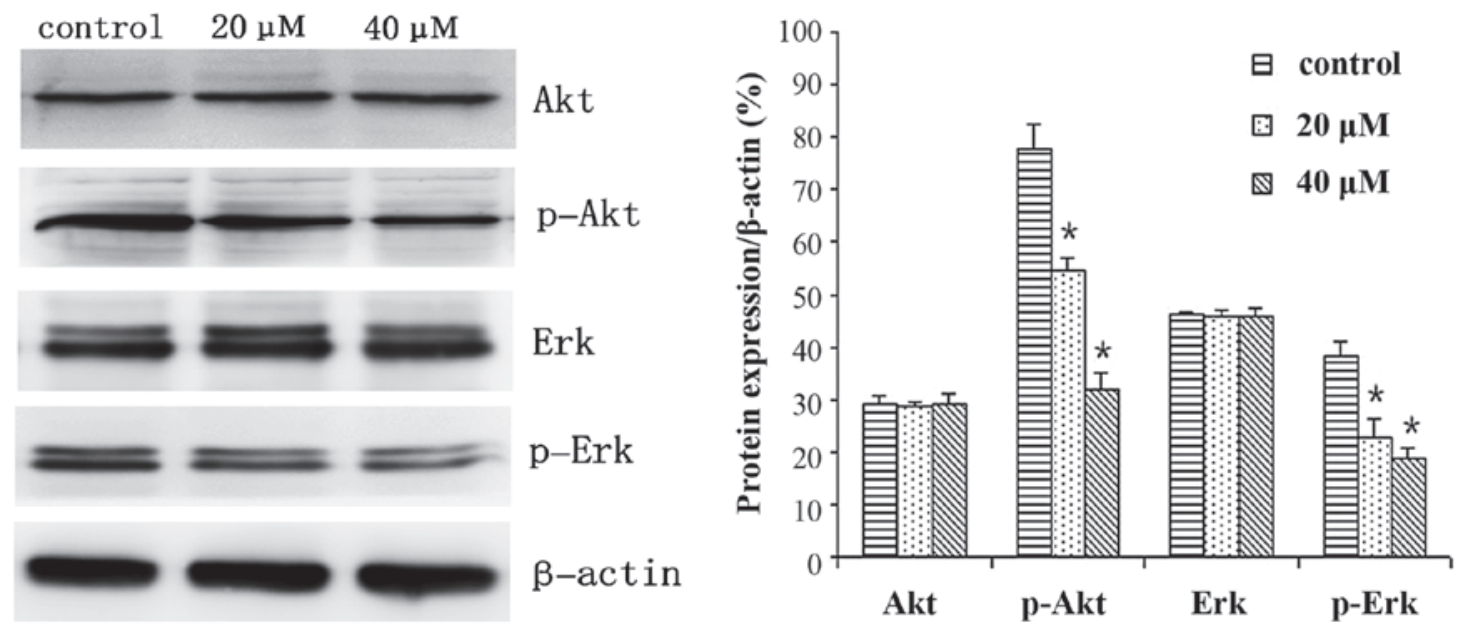

Figure 6. Isobavachalcone (IBC) regulates the expression of Akt, Erk and related proteins in MGC803 gastric cancer cells. Cells were treated with 0, 20 or $40 \mu \mathrm{M} \mathrm{IBC}$ for $48 \mathrm{~h}$. Data were derived from three independent experiments and are expressed as the mean \pm standard deviation. "P<0.05 vs. the control. Erk, extracellular signal-regulated kinase; p, phosphorylated.
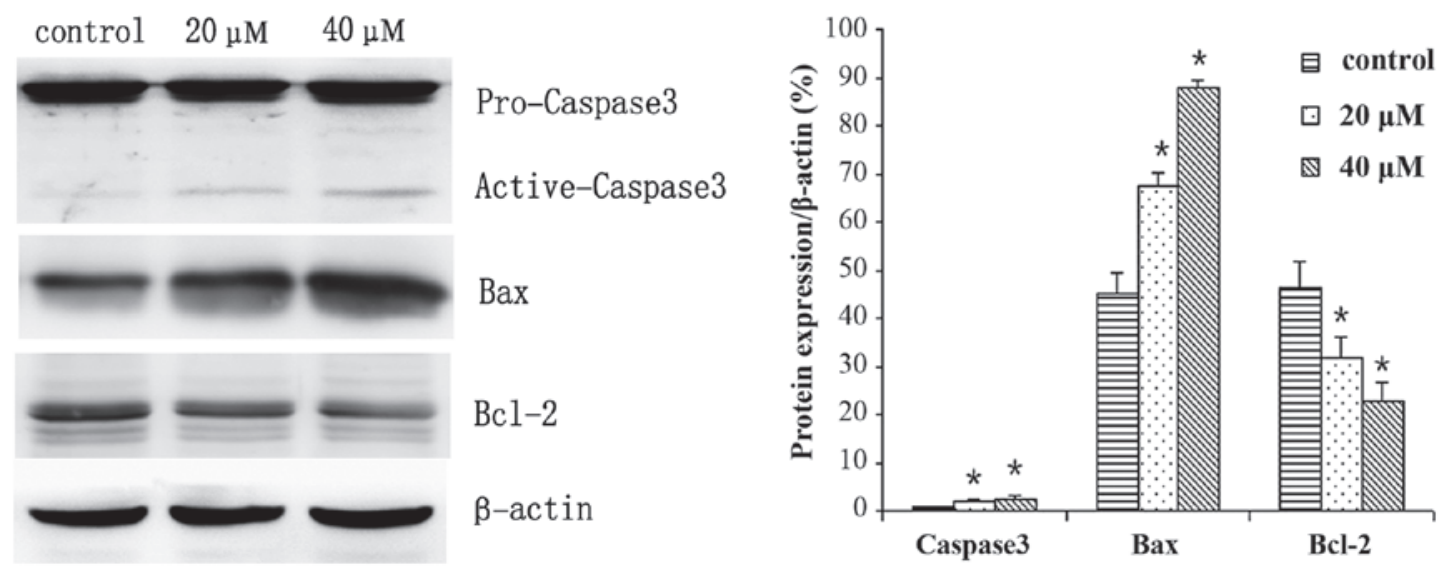

Figure 7. Isobavachalcone (IBC) regulates the expression of apoptosis-related proteins in MGC803 gastric cancer cells. Cells were treated with 0, 20 or $40 \mu \mathrm{M} \mathrm{IBC}$ for $48 \mathrm{~h}$. Data were derived from three independent experiments and are expressed as the mean \pm standard deviation. "P<0.05 vs. the control. Bcl-2, B-cell lymphoma-2; Bax, Bcl-2-associated X protein.

\section{Discussion}

IBC was first isolated from Psoralea corylifolia in 1968 by Bhalla et al (6). IBC is a chalcone, which possesses various features, including anti-inflammatory, anti-fungal and anti-reverse transcriptase activity (5). Previous studies have demonstrated that IBC also has good anti-tumor activity (7-9). Furthermore, a previous study demonstrated that IBC is capable of inducing apoptosis in human neuroblastoma cells, whereas no significant cytotoxicity was detected in normal rat cerebellar granule cells following treatment with the same dose of IBC (10). By observing various solid tumor cells and normal cell lines, including liver cells, L-02 cells and HUVECs, Jing et al (4) demonstrated that IBC had an obvious destructive effect on tumor cells, and notably, no toxic side effects were demonstrated in normal cells. These results indicated that IBC administration may be a highly efficient treatment for cancer patients with low toxicity.

The present study observed the effects of IBC on the proliferation of MGC803 gastric carcinoma cells, and the results demonstrated that IBC inhibited the proliferation of MGC803 cells in a concentration- and time-dependent manner. To verify whether the reduction in cell proliferation was associated with apoptosis, Wright-Giemsa staining was conducted to observe the morphology. MGC 803 cells were cultured in $20 \mu \mathrm{M} \mathrm{IBC}$ for $48 \mathrm{~h}$. Light microscopy detected the typical morphological features of apoptosis, including cytoplasmic condensation, pyknosis and the presence of apoptotic bodies. In order to validate the role of IBC in the promotion of apoptosis in gastric cancer cells, flow cytometric analysis was conducted in the present study. Flow cytometric analysis of early apoptosis demonstrated that the apoptotic rate of MGC803 cells was gradually increased with increasing IBC concentration. These results demonstrated that IBC may promote the apoptosis of MGC803 cells.

Invasion and metastasis are the most lethal features of cancer, accounting for $>90 \%$ of cancer-associated mortality (11). Distant organ or tissue metastasis is a marker of poor prognosis in patients with gastric cancer. The results of the present study demonstrated that various concentrations of IBC were capable of inhibiting the migratory and invasive ability of MGC803 cells, in a dose-dependent manner. However, the present study was inadequate in that only the 
phenomenon of IBC-induced inhibition of gastric cancer cell migration and invasion was observed, without further exploration of the specific molecular mechanisms; therefore, these investigations are required in future studies.

Apoptosis is a defensive mechanism of the body that eliminates malignant cells, and has a crucial role in the prevention of cancer. Notably, the predominant function of numerous antitumor drugs is the induction of apoptosis in tumor cells, via the regulation of various apoptosis-related signaling pathways (12-15).

The Bcl-2 family includes anti-apoptotic proteins, such as $\mathrm{Bcl}-2$, and proapoptotic proteins, such as Bax and $\mathrm{Bcl}-2$-associated death promoter (16). The Bcl-2 protein family has an important regulatory role in the release of cytochrome $c$ from mitochondria, which activates endogenous apoptosis pathways. Bax was the first protein to be identified that interacts with Bcl-2, and is capable of inhibiting the apoptosis-resisting ability of Bcl-2 $(17,18)$. The present study demonstrated that IBC decreased the protein expression levels of Bcl-2 and increased the protein expression levels of Bax to induce the apoptosis of gastric cancer cells.

The Akt signaling pathways have an important role in the survival of mammalian cells and resistance to apoptosis (19). As multicellular organisms, mammals maintain stable development through mutual checks and balances of proliferation and apoptosis, and if this balance is broken, it may lead to cancer. Previous studies have demonstrated that excessive activation of Akt affects the activity of each of the downstream effectors, thereby leading to resistance to apoptosis, and promoting the proliferation of tumor cells $(20,21)$. Various cellular stimulations are capable of activating Erk1/2, also known as p44/p42 mitogen activated protein kinase (MAPK); some may lead to the activation of transcription factors and others may activate cell proliferation, differentiation, cell cycle regulation and cell survival-associated serine/threonine protein kinase (15). Previous large phase I/II clinical trials have demonstrated that MAPK/Erk inhibitors are capable of prolonging the survival of patients with various types of cancer $(22,23)$. The results of the present study demonstrated that various concentrations of IBC successfully reduced the protein expression levels of p-Akt and p-Erk in MGC 803 cells. Jing et al (4) demonstrated that IBC may induce apoptosis in various tumor cells by inhibiting the activity of Akt signaling pathways, which was consistent with the results of the present study. Therefore, IBC may induce apoptosis in MGC803 cells via the Akt and Erk signaling pathways.

In conclusion, the results of the present study demonstrated that IBC was capable of inhibiting the proliferation of gastric cancer cells and the induction of apoptosis in a concentrationand time-dependent manner. Furthermore, IBC may inhibit the migratory and invasive ability of MGC803 cells. In terms of the underlying mechanisms, the results of the present study demonstrated that IBC induced apoptosis in gastric cancer cells by regulating apoptosis-related proteins and inhibiting Akt and Erk signaling pathways.

\section{Acknowledgements}

The present study was supported by The First Affiliated Hospital of Liaoning Medical University (Jinzhou, China). The authors would like to thank Professor Zhi-tu Zhu for valuable support.

\section{References}

1. Jemal A, Bray F, Center MM, Ferlay J, Ward E and Forman D: Global cancer statistics. CA Cancer J Clin 61: 69-90, 2011.

2. Guggenheim DE and Shah MA: Gastric cancer epidemiology and risk factors. J Surg Oncol 107: 230-236, 2013.

3. Cervantes A, RodaD, Tarazona N, Roselló S and Pérez-Fidalgo JA: Current questions for the treatment of advanced gastric cancer. Cancer Treat Rev 39: 60-67, 2013.

4. Jing $\mathrm{H}$, Zhou X, Dong X, Cao J, Zhu H, Lou J, Hu Y, He Q and Yang B: Abrogation of Akt signaling by Isobavachalcone contributes to its anti-proliferative effects towards human cancer cells. Cancer Lett 294: 167-177, 2010.

5. Akihisa T, Tokuda H, Hasegawa D, Ukiya M, Kimura Y, Enjo F, Suzuki T and Nishino H: Chalcones and other compounds from the exudates of Angelica keiskei and their cancer chemopreventive effects. J Nat Prod 69: 38-42, 2006.

6. Bhalla VX, Nayak UR and Dev S: Some new flavonoids from Psoralea corylifolia. Tetrahedron Lett 20: 2401-2406, 1968.

7. Szliszka E, Jaworska D, Ksek M, Czuba ZP and Król W: Targeting death receptor TRAIL-R2 by chalcones for TRAIL-induced apoptosis in cancer cells. Int J Mol Sci 13: 15343-15359, 2012.

8. Szliszka E, Czuba ZP, Mazur B, Sedek L, Paradysz A and Krol W: Chalcones enhance TRAIL-induced apoptosis in prostate cancer cells. Int J Mol Sci 11: 1-13, 2009.

9. Li W, Li S, Higai K, Sasaki T, Asada Y, Ohshima S and Koike K: Evaluation of licorice flavonoids as protein tyrosine phosphatase 1B inhibitors. Bioorg Med Chem Lett 23: 5836-5839, 2013.

10. Nishimura R, Tabata K, Arakawa M, Ito Y, Kimura Y, Akihisa T, Nagai H, Sakuma A, Kohno H and Suzuki T: Isobavachalcone, a chalcone constituent of Angelica keiskei, induces apoptosis in neuroblastoma. Biol Pharm Bull 30: 1878-1883, 2007.

11. Jin X, Zhu Z and Shi Y: Metastasis mechanism and gene/protein expression in gastric cancer with distant organs metastasis. Bull Cancer 101: E1-E12, 2014.

12. Khan KH, Blanco-Codesido $M$ and Molife LR: Cancer therapeutics: Targeting the apoptotic pathway. Crit Rev Oncol Hematol 90: 6200-219, 2014.

13. Westin JR: Status of PI3K/Akt/mTOR pathway inhibitors in lymphoma. Clin Lymphoma Myeloma Leuk 14: 335-342, 2014.

14. Koehler BC, Jäger D and Schulze-Bergkamen H: Targeting cell death signaling in colorectal cancer: Current strategies and future perspectives. World J Gastroenterol 20: 1923-1934, 2014.

15. Aranda F, Vacchelli E, Eggermont A, , Galon J, Fridman WH, Zitvogel L, Kroemer G and Galluzzi L: Trial Watch: Immunostimulatory monoclonal antibodies in cancer therapy. Oncoimmunology 3: e27297, 2014.

16. Park JW, Choi YJ, Suh SI, Baek WK, Suh MH, Jin IN, Min DS, Woo JH, Chang JS, Passaniti A, Lee YH and Kwon TK: Bcl-2 overexpression attenuates resveratrol-induced apoptosis in U937 cells by inhibition of caspase-3 activity. Carcinogenesis 22: 1633-1639, 2001 .

17. Sharawat SK, Bakhshi R, Vishnubhatla S, Gupta R and Bakhshi S: $\mathrm{BAX} / \mathrm{BCL} 2 \mathrm{RMFI}$ ratio predicts better induction response in pediatric patients with acute myeloid leukemia. Pediatr Blood Cancer 60: E63-E66, 2013.

18. Sjöström J, Blomqvist C, von Boguslawski K, Bengtsson NO, Mjaaland I, Malmström P, Ostenstadt B, Wist E, Valvere V, Takayama S, Reed JC and Saksela E: The predictive value of bcl-2, bax, bcl-xL, bag-1, fas and fasL for chemotherapy response in advanced breast cancer. Clin Cancer Res 8: 811-816, 2002.

19. Dent P: Crosstalk between ERK, AKT and cell survival. Cancer Biol Ther 15: 245-246, 2014.

20. Briest F and Grabowski P: PI3K-AKT-mTOR-signaling and beyond: The complex network in gastroenteropancreatic neuroendocrine neoplasms. Theranostics 4: 336-365, 2014.

21. Polivka J Jr and Janku F: Molecular targets for cancer therapy in the PI3K/AKT/mTOR pathway. Pharmacol Ther 142: 164-175, 2014.

22. McCubrey JA, Steelman LS, Kempf CR, Chappell WH, Abrams SL, Stivala F, Malaponte G, Nicoletti F, Libra M, Bäsecke J, et al: Therapeutic resistance resulting from mutations in $\mathrm{Raf} / \mathrm{MEK} / \mathrm{ERK}$ and PI3K/PTEN/Akt/mTOR signaling pathways. J Cell Physiol 226: 2762-2781, 2011.

23. Infante JR, Fecher LA, Falchook GS, Nallapareddy S, Gordon MS, Becerra C, DeMarini DJ, Cox DS, Xu Y, Morris SR, et al: Safety, pharmacokinetic, pharmacodynamic, and efficacy data for the oral MEK inhibitor trametinib: A phase 1 dose-escalation trial. Lancet Oncol 13: 773-781, 2012. 